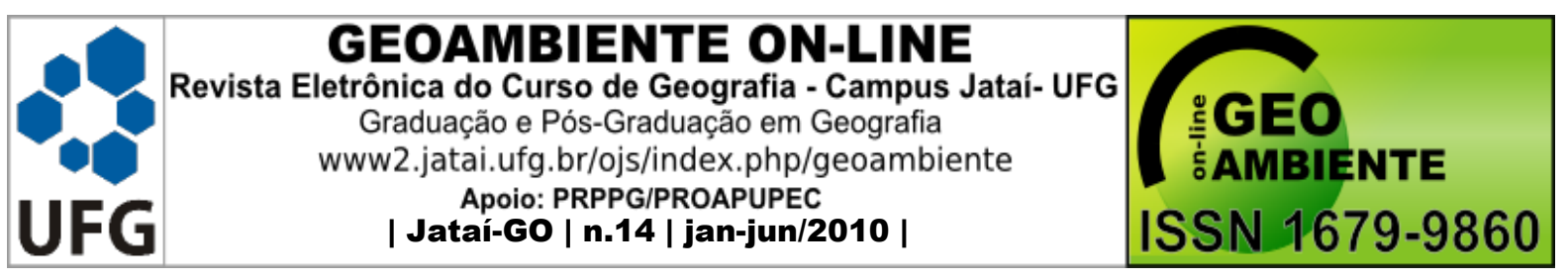

\title{
DIAGNÓSTICO PRELIMINAR DE IMPACTOS AMBIENTAIS NO TRECHO URBANO DO CÓRREGO SÃO JOÃO EM PORTO NACIONAL, ESTADO DO TOCANTINS
}

\author{
Ercília de Sena Araújo ${ }^{1}$; Marília de Paula Barbosa ${ }^{1}$
}

(1 - Mestranda do programa de Pós-graduação em Ecologia de Ecótonos - Fundação Universidade Federal do Tocantins, Rua 03, Quadra 17 - Jardim dos Ipês, CEP - 77500-000, Porto Nacional, TO, erciliasena@ hotmail.com)

\section{Resumo}

A sub-bacia do córrego São João drena o município de Porto Nacional na região central do Estado do Tocantins, sendo um dos tributários do Rio Tocantins. Devido à intensa pressão antrópica sofrida pelo seu trecho urbano, este trabalho visa avaliar o grau de impacto antrópico a fim de subsidiar futuras políticas públicas de conservação. Para atingir tais objetivos, foi realizado um diagnóstico visual por meio da aplicação do protocolo de avaliação rápida in situ. Embora haja inquestionáveis modificações ambientais (resíduos sólidos, remoção da mata ciliar, erosão, assoreamento, espécies exóticas, aporte de esgoto), o trecho urbano do córrego São João ainda apresenta relevância ecológica e social.

Palavras-chave: Degradação ambiental; Avaliação ecológica rápida; Impacto Antrópico.

\section{Abstract \\ PRELIMINARY ANALYSIS OF ENVIRONMENTAL IMPACTS IN URBAN PORTION OF THE STREAM SÃO JOÃO IN PORTONACIONAL, STATE OF TOCANTINS - BRAZIL}

The sub-basin of the stream São João drains Porto Nacional city in central state of Tocantins, being one of the tributaries of the Tocantins river. Due to intense human pressure suffered by

\footnotetext{
Artigo recebido para publicação em 23 de Dezembro de 2009;

Artigo aprovado para publicação em 26 de junho de 2010.
} 


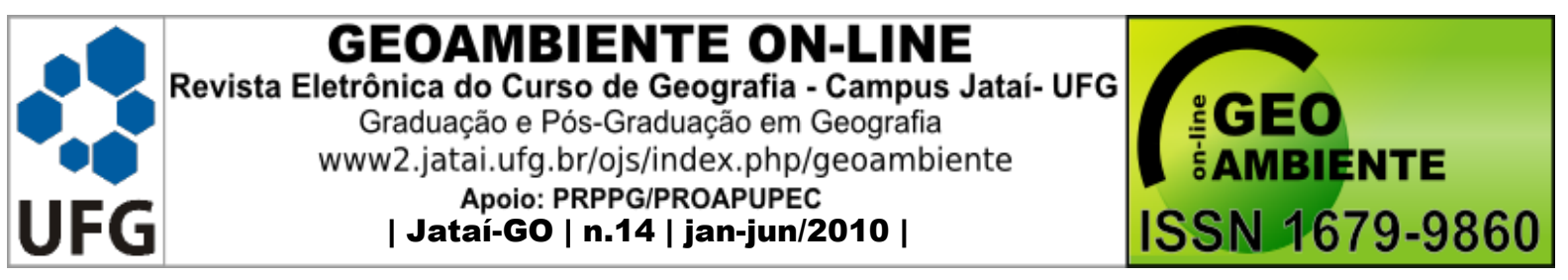

their urban stretch of this work is to evaluate the degree of human impact order to support future conservation policies. To achieve these objectives were used a visual diagnosis by rapid assessment protocol in situ proposed by Callisto et al., (2002). While there are undoubted environmental change (solid waste, removal of riparian vegetation, erosion, siltation, exotic species, supply of sewage), the stretch urban stream São João still has important ecological and social.

Keywords: Degradation environmental; Rapid ecological assessment; Human Impact.

\section{Resumen}

ANÁLISIS PRELIMINAR DE IMPACTO AMBIENTAL EN PORCIÓN URBANA DEL ARROYO SÃO JOÃO EN PORTO NACIONAL, ESTADO DEL TOCANTINS - BRAZIL

La sub-cuenca del arroyo San Juan drena el municipio de Puerto Nacional en La región central del estado de Tocantins, y es uno de los afluentes del Río Tocantins. Debido a la intensa presión humana que sufren por su tramo urbano, este estudio pretende evaluar el grado de impacto humano a fin de apoyar las futuras políticas de conservación. Para lograr estos objetivos, se realizó un diagnóstico visual mediante la aplicación del protocolo de evaluación rápida sobre el terreno. Si bien existen indudables cambios ambientales (residuos sólidos, la eliminación de la vegetación ribereña, la erosión, la sedimentación, las especies exóticas, los vertidos de aguas residuales), el tramo urbano del arroyo de San Juan aún tiene relevancia social y ecológica.

Palabras - clave: Degradación ambiental, Evaluación ecológica rápida, Impacto humano.

\section{1 - Introdução}

A sub-bacia do córrego São João drena o município de Porto Nacional na região central do Estado do Tocantins, sendo um dos tributários do Rio Tocantins. O córrego São João nasce na região denominada de "Serra" do Carmo e deságua no lago da Usina Hidrelétrica de Lajeado (BORGES \& BERTOLIN, 2002). A cobertura vegetal predominante ao longo do leito do córrego São João é o cerrado com presença de mata de galeria. 


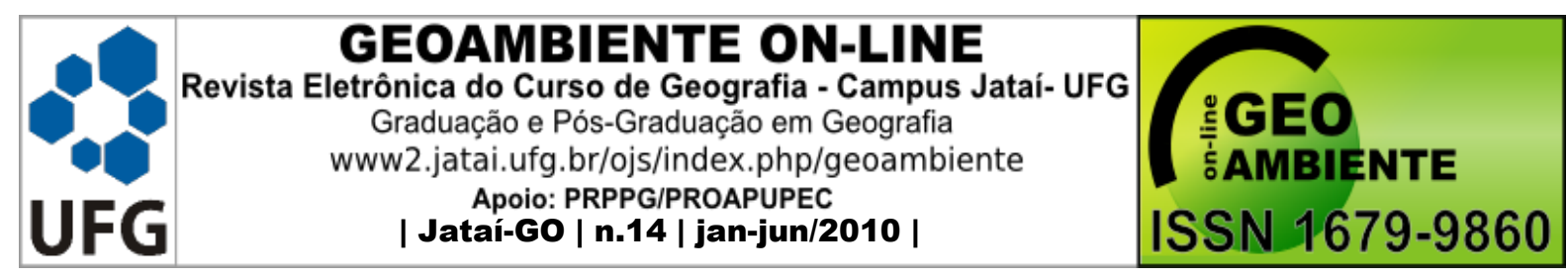

Com a expansão das cidades há aumento da pressão antrópica sobre os corpos hídricos inseridos nessas, pela ocupação do entorno. Isto ocorre, entre outros fatores, devido aos benefícios que estes corpos oferecem, tais como amenização da temperatura, pesca de subsistência e lazer. Entretanto, o uso desordenado do solo e da água, o despejo de resíduos sólidos e a retirada da mata ciliar são alguns dos fatores que atuam na modificação dos ambientes naturais (GOLDANI \& CASSOL, 2008).

A falta de políticas públicas é um agravante por culminar na falta de planejamento do uso dos recursos hídricos, do solo e das matas ciliares. O processo de degradação da mata ciliar resulta na perda quali-quantitativa da água, biodiversidade (GLOAGEN et al., 2007), controle da erosão, redução dos efeitos de enchentes, filtragem de resíduos químicos e sólidos.

Um método largamente utilizado para mensurar o nível dos impactos antrópicos é o método de protocolos de avaliação rápida. Este é um importante instrumento de diagnóstico de alteração ambiental, por ser de fácil aplicação e pouco dispendiosa, mostrando-se viável e de larga aceitação no meio científico (CALLISTO et al., 2002).

Neste contexto, o presente trabalho teve por objetivo avaliar o grau de impacto antrópico no trecho urbano do córrego São João no município de Porto Nacional, Estado do Tocantins, a fim de subsidiar futuras políticas públicas de conservação.

\section{2 - Métodos}

Para a seleção dos pontos de amostragem foram realizadas visitas iniciais à área (Figura 1), determinando-se assim três pontos de coletas: o primeiro ponto está localizado nas coordenadas geográficas $10^{\circ} 42^{\prime} 07.27^{\prime \prime} \mathrm{S} / 48^{\circ} 23^{\prime} 49.75^{\prime \prime} \mathrm{O}$, enquanto que o segundo ponto localiza-se a $10^{\circ} 42^{\prime} 02.91^{\prime \prime} \mathrm{S} / 48^{\circ} 24^{\prime} 18.92^{\prime \prime} \mathrm{O}$, e o terceiro ponto é na foz do ribeirão a $10^{\circ} 41^{\prime} 52.96 " \mathrm{~S} / 48^{\circ} 24 ' 43.60 " \mathrm{O}$, onde deságua no reservatório da usina hidroelétrica Luís Eduardo Magalhães (UHE Lajeado). Para avaliar o grau de degradação dos pontos amostrados realizou-se um diagnóstico visual por meio da aplicação do protocolo de avaliação rápida in 


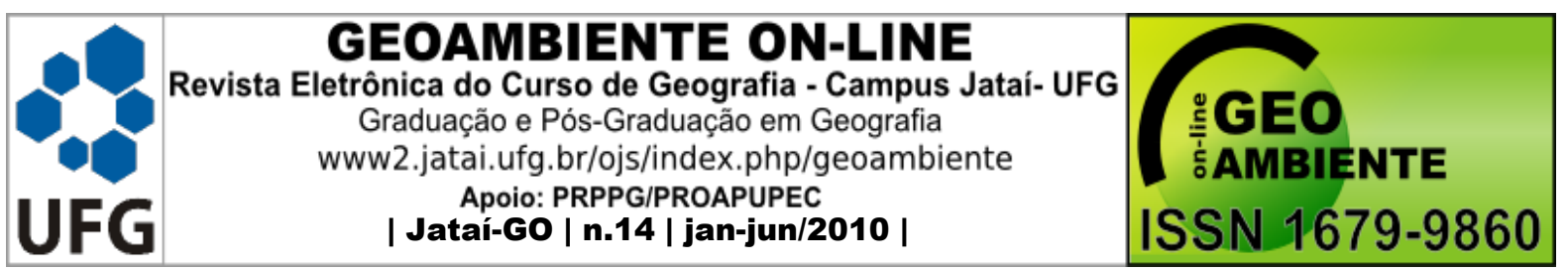

situ proposto por Callisto et al., (2002). A metodologia aplicada foi amparada por documentos fotográficos dos locais de estudo.

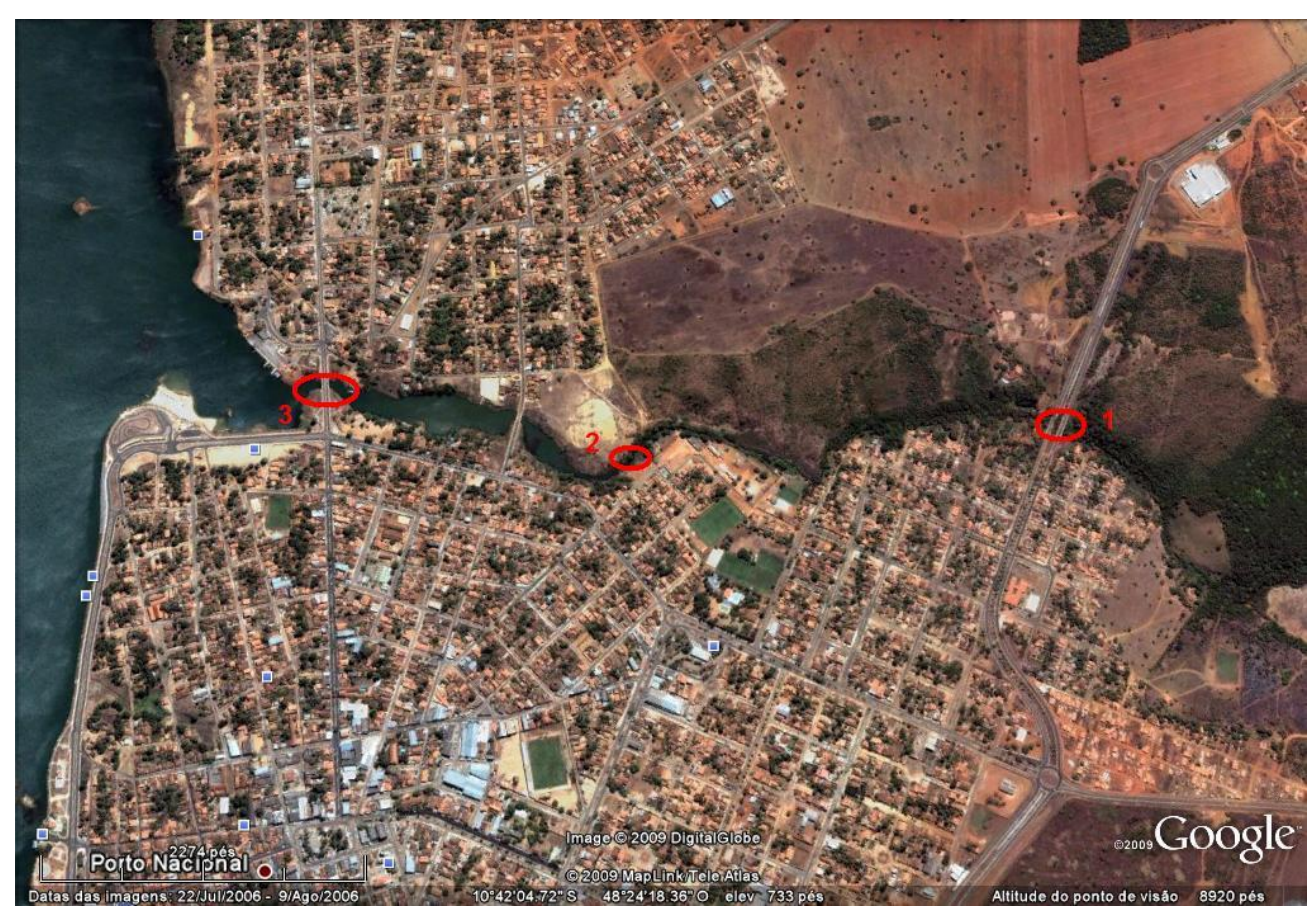

Figura 1 - Imagem de satélite do trecho urbano do córrego São João em Porto Nacional. Fonte: Google Earth.

O protocolo de avaliação rápida, segundo Callisto et al., (2002), aplicado neste estudo, é baseado em um diagnóstico visual por meio da discriminação do grau de alteração dos atributos água, solo e vegetação. Dentro do protocolo proposto, avaliam-se as características dos pontos do córrego, o grau de impactos como resultado de atividades antrópicas, bem como as condições do ambiente e o nível de conservação das condições naturais.

Diferentes categorias, cada uma com um conjunto de parâmetros, foram contempladas na avaliação do protocolo. A estas, foram atribuídas pontuações que variam de 0 a 5 de acordo com as observações das condições ambientais. O valor final foi obtido pela somatória das médias atribuídas a cada parâmetro, independentemente. O resultado das 


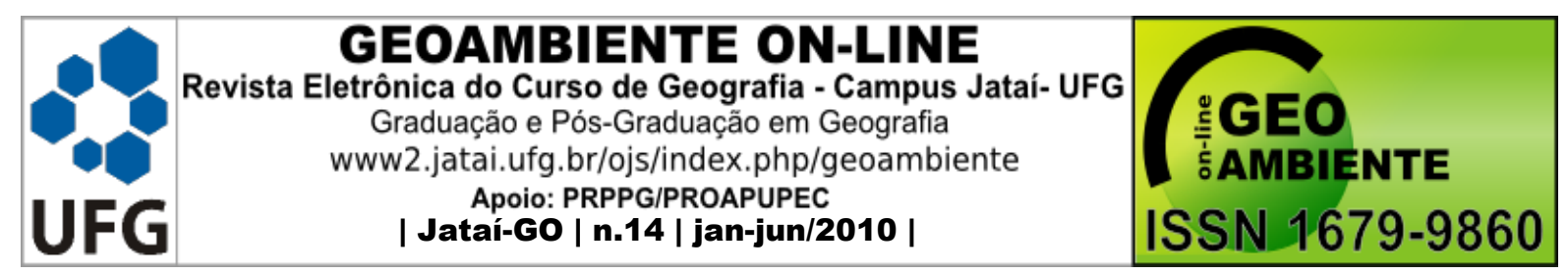

pontuações para cada local reflete, portanto, o nível de preservação das condições ecológicas desses, sendo que de 0 a 40 pontos representa áreas "impactadas", 41 a 60 áreas "alteradas", e acima de 61 pontos, áreas "naturais".

\section{3 - Resultados e discussão}

A aplicação do protocolo de avaliação rápida gerou uma tabela (1) com a média da pontuação para os 22 parâmetros avaliados nos 3 pontos de coletas.

Tabela 1: Resultados da aplicação do protocolo no córrego São João (Porto Nacional- TO).

\section{Parâmetros}

\section{Ponto 1}

Ponto 2

Pontuação

\begin{tabular}{|c|c|c|c|}
\hline $\begin{array}{c}\text { Tipo de ocupação das } \\
\text { margens do corpo } \\
\text { d'água. }\end{array}$ & 0 & 0 & 0 \\
\hline $\begin{array}{l}\text { Erosão próxima e/ou } \\
\text { nas margens do rio. }\end{array}$ & 0 & 0 & 2 \\
\hline $\begin{array}{l}\text { Assoreamento no leito } \\
\text { do rio. }\end{array}$ & 2 & 2 & 2 \\
\hline Alterações antrópicas. & 4 & 4 & 0 \\
\hline $\begin{array}{c}\text { Cobertura vegetal no } \\
\text { leito. }\end{array}$ & 4 & 3 & 4 \\
\hline Odor da água & 4 & 2 & 2 \\
\hline Oleosidade da água. & 2 & 2 & 2 \\
\hline $\begin{array}{c}\text { Transparência da } \\
\text { água. }\end{array}$ & 4 & 4 & 4 \\
\hline Odor do sedimento & 4 & 3 & 3 \\
\hline Oleosidade do fundo. & 4 & 2 & 4 \\
\hline Tipo de fundo. & 5 & 3 & 0 \\
\hline Extensão dos rápidos. & 3 & 2 & 0 \\
\hline $\begin{array}{l}\text { Freqüuência dos } \\
\text { rápidos. }\end{array}$ & 4 & 2 & 0 \\
\hline Tipo de substrato. & 2 & 0 & 0 \\
\hline Deposição de lama. & 5 & 0 & 3 \\
\hline $\begin{array}{c}\text { Depósitos } \\
\text { sedimentares. }\end{array}$ & 2 & 2 & 2 \\
\hline Alterações no canal do & 2 & 2 & 2 \\
\hline
\end{tabular}




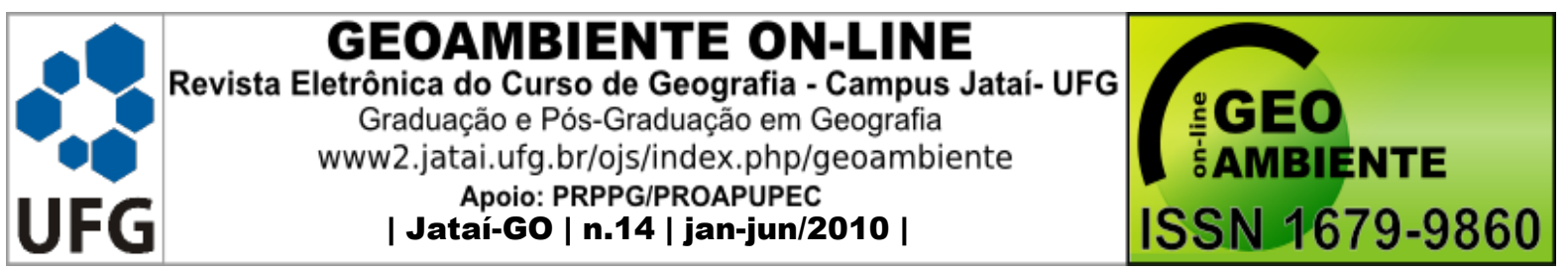

rio.

$\begin{array}{cccc}\begin{array}{c}\text { Característica do fluxo } \\ \text { da água. }\end{array} & 0 & 3 & 5 \\ \begin{array}{c}\text { Presença de mata } \\ \text { ciliar. }\end{array} & 3 & 2 & 0 \\ \begin{array}{c}\text { Estabilidade das } \\ \text { margens. }\end{array} & 0 & 2 & 2 \\ \begin{array}{c}\text { Extensão da mata } \\ \text { ciliar. }\end{array} & 3 & 1 & 0 \\ \begin{array}{c}\text { Presença de plantas } \\ \text { aquáticas. }\end{array} & 0 & 3 & 3 \\ \text { Pontuação } & 57 & 44 & 40\end{array}$

\begin{tabular}{ccccccc}
\multicolumn{2}{c}{ Avaliação } & \multicolumn{2}{c}{ Alterado } & \multicolumn{2}{c}{ Alterado } & \multicolumn{2}{c}{ Impactado } \\
\hline Dos pontos analisados, o ponto 1 destaca-se por & ser & o menos antropizado,
\end{tabular}
apresentando a maior pontuação obtida. Neste ponto há uma ponte, presença de resíduos sólidos, plantas invasoras e um intenso processo erosivo culminando em um grave assoreamento (Figura 2A). Embora seja classificado como "alterado", sua mata ciliar (Figura 2B) possui maior extensão em relação aos outros pontos, em alguns trechos cobrindo parcialmente o leito do córrego. Visualizou-se a ocorrência de residências, que juntamente com a ponte que cruza o córrego resulta na fragmentação do ambiente, tornando-o mais vulnerável.

A)

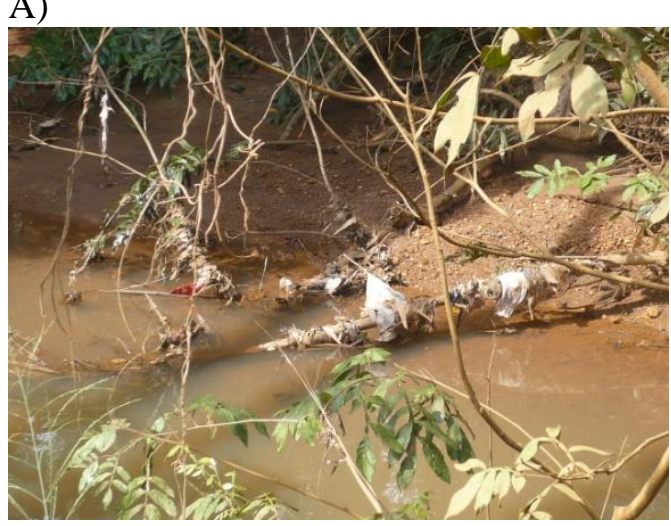

B)

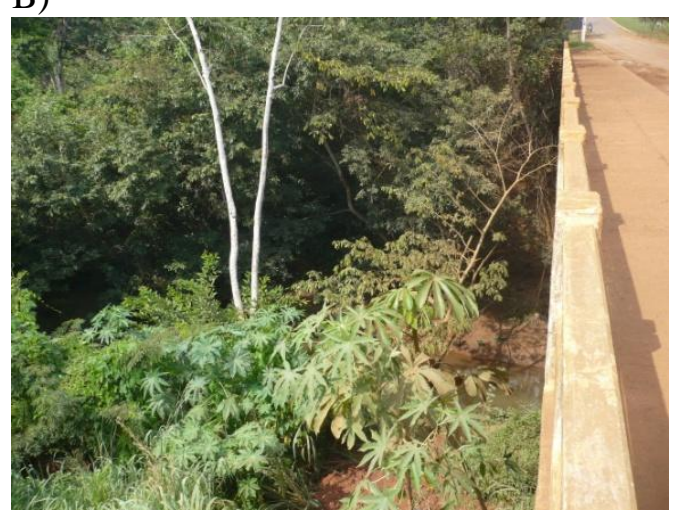

Figura 2 - A) córrego São João com destaque para a presença de assoreamento e resíduos sólidos; B) área com vegetação razoavelmente preservada. 


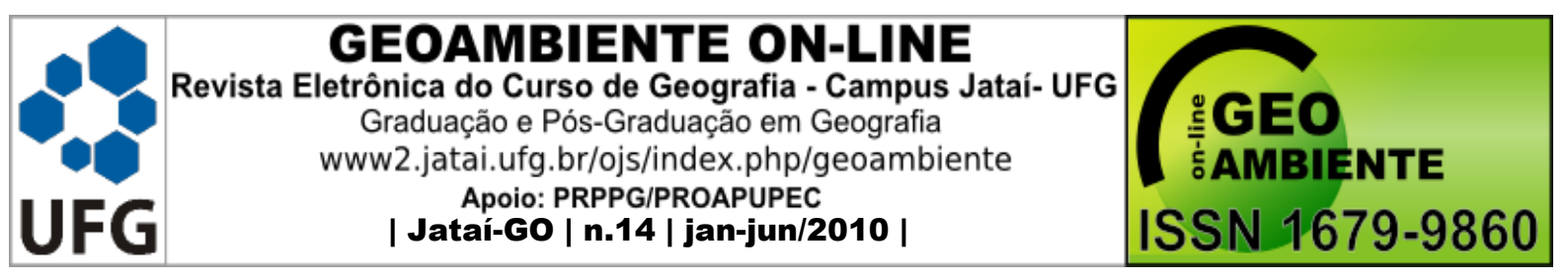

O ponto 2 recebeu avaliação de "alterado", porém com baixa pontuação. Isso provavelmente deve-se ao processo de degradação do ambiente devido, principalmente, à ocupação desordenada pela circunvizinhança. Esta ocupação, muitas vezes, invade a mata ciliar, o que se reflete na pequena ou até mesmo inexistência desta vegetação. Tal fato ocasiona o aumento do processo erosivo provocando, por sua vez, o assoreamento do leito (Figura. 3). Além desse, outros problemas decorrentes da interferência antrópica são: presença de resíduos sólidos e a colonização por espécies exóticas.

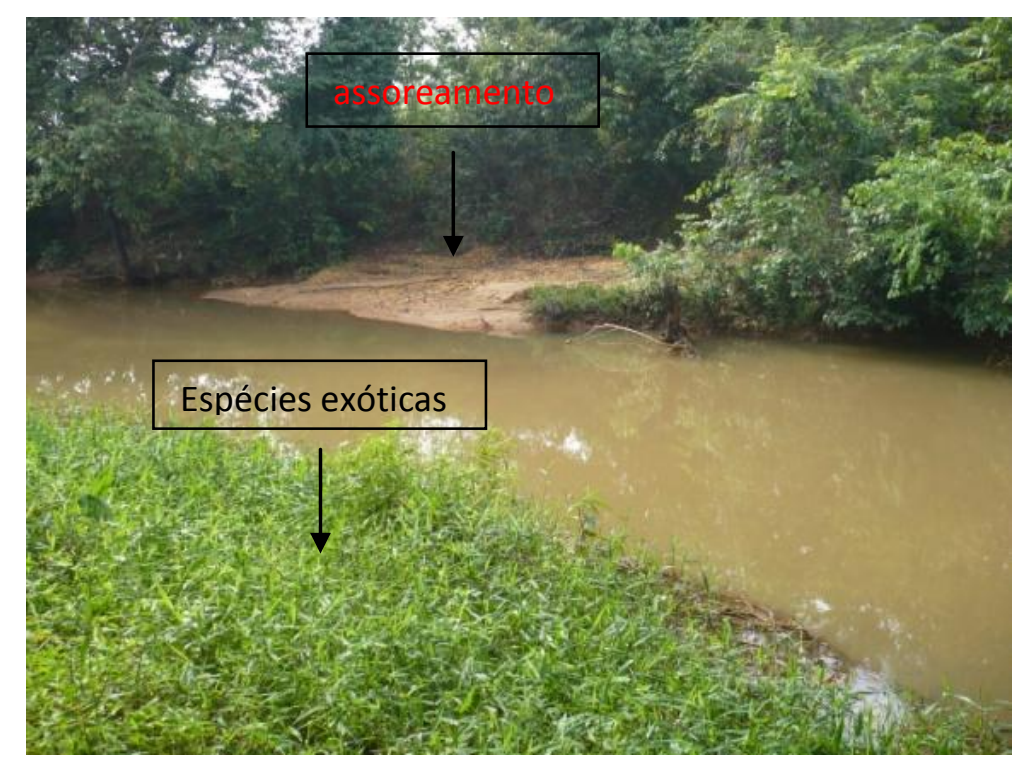

Figura 3 - Depósito de material na margem direita do rio e espécies exóticas na margem esquerda.

Segundo a pontuação, o ponto 3 é o que encontra-se com maior grau de degradação, recebendo assim a avaliação de "impactado". Tal resultado reflete as massivas pressões antrópicas exercidas na área, tais como: presença de resíduos sólidos, construção de residências dentro da área de proteção (Figura 4), alteração intensiva do canal com a inserção de grandes rochas, como tentativa de conter a erosão nas proximidades de uma ponte, formação de remansos decorrentes da implantação do reservatório da UHE Lajeado. 


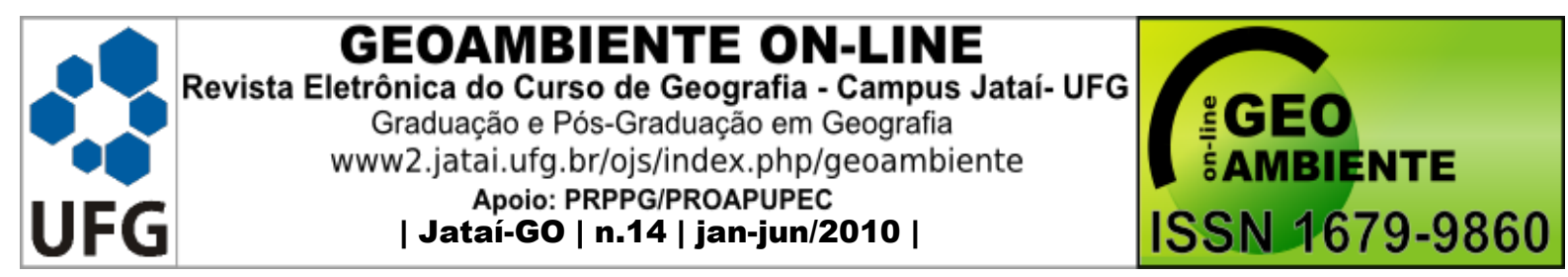

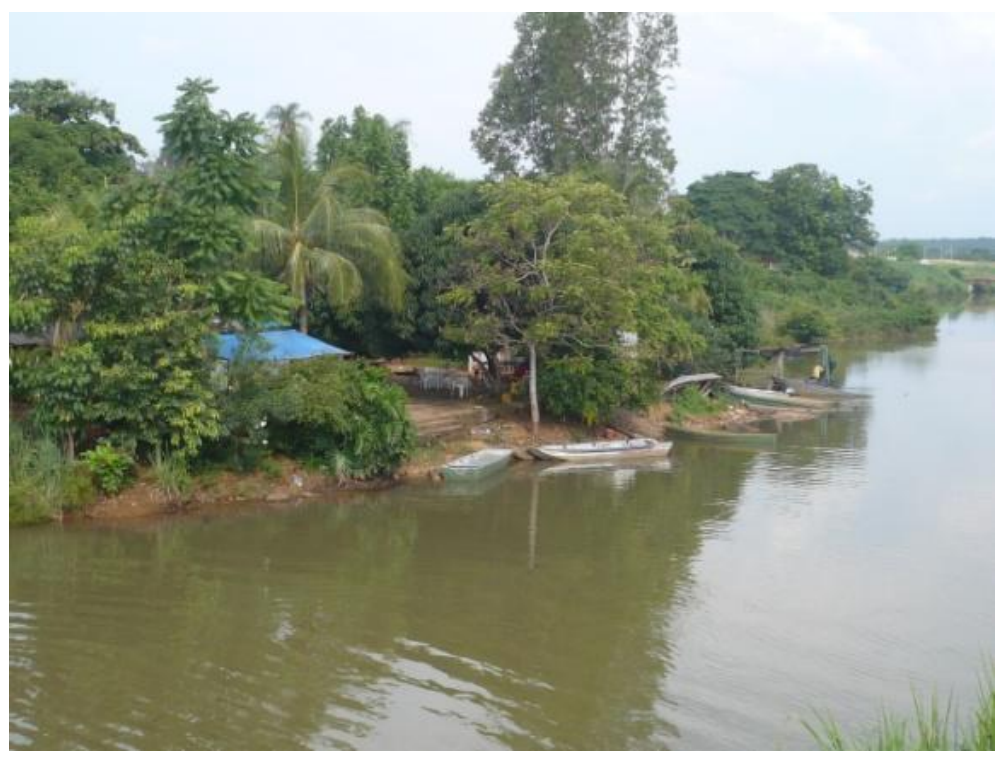

Figura 4 - Exemplo de ocupação das margens do rio a partir da construção de casas de recreação.

É notória a importância da cobertura vegetal para a proteção dos cursos hídricos, controlando, entre outras funções, a erosão das margens, sendo que quanto maior e mais diversificada a mata ciliar, maior a capacidade do sistema em termos de reserva hídrica (Primavesi e Primavesi, 2003). Porém detectou-se no ponto 3 a retirada significativa da mata ciliar e o local foi intensamente colonizado por espécies exóticas.

Os parâmetros que obtiveram menores pontuações nos três pontos são os que se referem à ocupação das margens, intensidade de erosão e assoreamento. Tal resultado corrobora com os encontrados por Rodrigues (2008) que aponta a conservação das margens como fator problemático para o trecho urbano do ribeirão do Funil em Ouro Preto, Minas Gerais. Além disso, os locais estudados apresentam sinais de poluição, como oleosidade e odor da água e a presença de resíduos sólidos, o que está entre as principais características que impedem a utilização do recurso hídrico em trechos urbanos de cursos d'água (Martins, 2004).

\section{4 - Considerações finais}




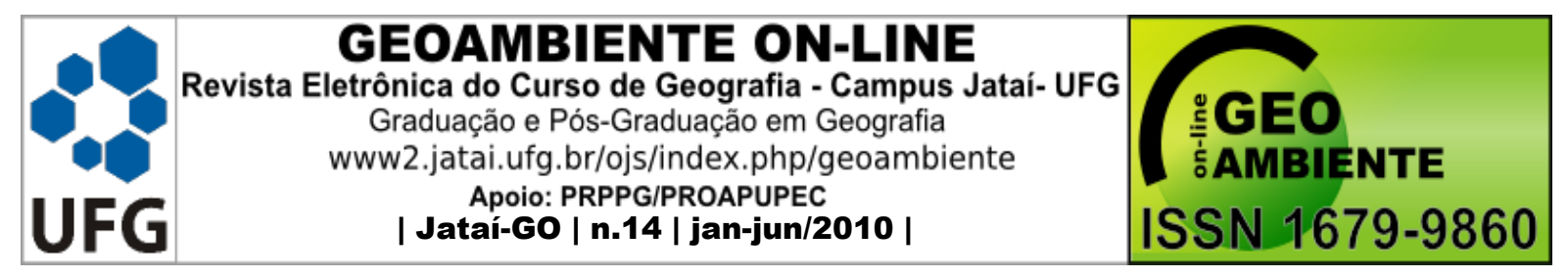

As avaliações revelam que embora haja inquestionáveis modificações ambientais, inclusive o aporte de esgoto, o trecho urbano do córrego São João ainda apresenta relevância ecológica e social. Embora nenhum dos pontos tenha recebido classificação de área "natural", tratam-se de ambientes com relativa heterogeneidade devido a regiões com a presença de plantas aquáticas, troncos, galhos e a alternância entre ambientes com rápidos e remansos.

É oportuno ressaltar que o trecho do córrego é importante por contribuir para a subsistência da população ribeirinha que explora os recursos tanto de origem vegetal como animal. Além disso, o curso d'água contribui para amenizar o clima, proporcionando maior bem-estar para a população.

Finalmente, por se tratar de uma Área de Preservação Permanente e, portanto, amparada pela lei federal que instituiu o Código Florestal, se faz necessária a implantação de políticas públicas eficazes no sentido de restabelecer a integridade do sistema em questão.

\section{5 - Referências}

CALliSTO, M.; FERREIRA, W. R.; MORENO P.; GOULART M.; PETRUCIO M. Aplicação de um protocolo de avaliação rápida da diversidade de habitats em atividade de ensino e pesquisa (MG-RJ). Acta Limnologica Brasiliensia. v. 14, n. 1, p. 91-98, 2002.

BORGES, K. P.; BERTOLIN, A. O. Avaliação microbiológica da qualidade da água do córrego São João, Porto Nacional-TO, Brasil. Holos Environment. v. 2, n. 2, p.174-184, 2002.

GLOAGEN, R. A. B. G.; MELO FILHO, J. F.; SILVA, P. S. O.; DOURADO, C. S.; SILVA JÚNIOR, J. J.; SOUZA, D. L. A. Diagnóstico preliminar de impactos ambientais na microbacia do ribeirão do Machado em Cruz das Almas - BA. Revista Brasileira de Agroecologia. v. 2, n. 2, p. 1645-1648, 2007.

GOLDANI, J. Z.; CASSOL, R. Ocupação antrópica e socio-ambiental da microbacia do rio Vacacaí- Mirim - RS. Geomática Santa Maria. v. 3, n. 1 e 2, p. 43-55, 2008.

MARTINS, S. V. Recuperação de matas ciliares. $2^{\text {a }}$ Ed. Revista e ampliada. Viçosa: Editora Aprenda Fácil, 2007, 255p. 


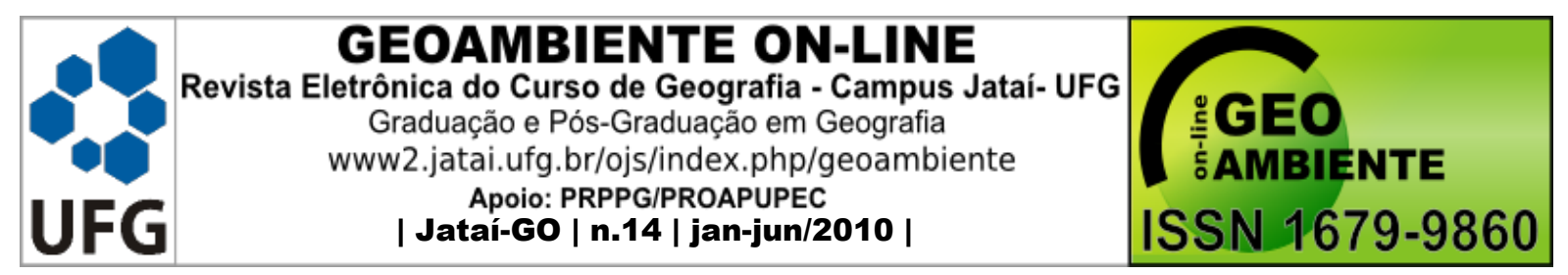

MARTINS, J. P. S. Água e cidadania em Campinas e região: o desafio do século 21. Campinas/SP: SANASA, 2004

RODRIGUES, A. S. L. Adequação de um Protocolo de Avaliação Rápida para o monitoramento e avaliação ambiental de cursos d'água inseridos em campos rupestres. [Dissertação de Mestrado] - Ouro Preto: Escola de Minas, Universidade Federal de Ouro Preto; 2008.

PRIMAVESI, O.; PRIMAVESI, A. Fundamentos ecológicos para o manejo efetivo do ambiente rural nos trópicos: educação ambiental e produtividade com qualidade. São Carlos: Embrapa Pecuária Sudeste, 2003. 